discredit upon his calculations by stating that "the accuracy of the results ascertained and shown by the tables are to a considerable extent necessarily hypothetical, and are not of course gnaranteed to the contributors." This admission of itself was sufficient to condemn the whole plan; for no set of tables could be safely adopted in the construction of which hypothetical data had been employed. There are, however, suggestions in the pamphlet referred to which I have found useful, notwithstanding the impracticability and complicated nature of the plan, which fixes no precise time for the liquidation of individual elaims, but regulates such period according to the age of the youngest member on the books.

In concluding this article, I may be permitted to observe, that the habit of generalizing too hastily and drawing inferences from numbers too small to admit of fair averages has often been productive of error. The tables, however, which have been constructed from the census returns, are entirely free from objection on this ground, while the conclusions which have been arrived at could searcely have been misinterpreted. Doubtlessly even more precise information will be acquired relating to the conjugal eondition by means of the next decennial returns; and the conjugal aspect of society, as it applies to the upper, middle, and lower ranks of saciety (if these distinctions of rank or any other for a similar parpose can be well defined), will be thoroughly ascertained.

$$
\text { 40, King William Street, London Bridge, }
$$
August 17th, 1855.

GEORGE SCOTT.

\title{
ON THE MEANS OF APPROXIMATING TO THE RATE OF INTEREST YIELDED BY OERTAIN INVESTMENTS, \&c.
}

\section{To the Editor of the Assurance Magazine.}

Sir,- Although the following problem is one which mast frequently present itself to persons who have occasion to estimate the comparative advantages of different investments, \&e., I am not aware that a convenient mode of solving it has ever been pointed out.

Problem.-A bond securing an advance of $£ 1$ at $\rho$ per annam is purchased for $\mathfrak{L} 1+p$ exactly $n$ years before the principal becomes repayable, and immediately after a year's interest has been received by the seller. What is the rate of interest obtained by the purchaser?

Let $r=$ the rate of interest sought, then $1+p=\frac{1-(1+r)^{-n}}{r} \cdot p+$

$$
\begin{aligned}
(1+r)^{-n}, \text { or } p & =\frac{1-(1+r)^{-n}}{r}(\rho-r) . \\
\text { Again, let } \phi r & =\frac{1-(1+r)^{-n}}{r}(\rho-r)-p \quad[1],
\end{aligned}
$$

or $\phi r=0$; and let $r=r_{1}+h$ where $r_{1}$ is an assumed near value of $r$ and $h$ the difference between it and the correct value. Expanding the lefthand member of the equation $\phi\left(r_{1}+h\right)=0$, we have $\phi r_{1}+\phi^{\prime} r_{1} h+\ldots=0$, or $h=-\frac{\phi r_{1}}{\phi^{\prime} r_{1}}$ (nearly, when $h$ is small); that is, an approximate value of $h$ may be found by substituting the assumed value $r_{1}$ for $r$ in the righthand member of Equation [1], dividing the expression so obtained by its differential coefficient, and changing the sign of the resnlt. Performing these operations, we shall find 


$$
h=r_{1} \frac{a_{-n}\left(\rho-r_{1}\right)-p}{a_{-n} \cdot \rho-n s_{-\overline{n+1}}\left(\rho-r_{1}\right)} \quad[2] ;
$$

$s_{-n}$ being the present value of a sum ( $£ 1$ ) due at the end of $n$ years, and $a_{-n}$ the present value of an annuity of $£ 1$ for that period, at the assumed rate of interest $r_{1} \cdot *$

The above expression affords the means of obtaining a convenient formula for a first approximation; for by making $r_{1}=\rho$, the equation becomes

$$
h=-\frac{p}{a_{-n}} \text { or } r=\rho-\frac{p}{a_{-n}} \quad[3] .
$$

We may thus with ease find an approximate value of $r$, which, if not sufficiently exact itself, will serve for obtaining a more correct value by means of Equation [2].

It should be observed that, having obtained this first approximation by Equation [3], and proceeding, if necessary, to find a more correct value by Equation [2], the labour of the latter operation will be considerably lessened if, instead of using the exact quantity given by Equation [3], we take the rate nearest to it for which we have tabulated values of $s_{-n}$ and $a_{-n}$. As the public is now in possession of interest tables for every $\frac{1}{4}$ of $f 1$ per cent. within the limits of practicable rates, this course will generally suffice; but if from any cause it is necessary to compute the values of $s_{-n}$ and $a_{-n}$, it will perhaps be more convenient to put Equation [2] in the following form, to which it is reducible by simply maltiplying the numerator and denominator by $r_{1}$ :-

$$
h=r_{1} \frac{\left(1-s_{-n}\right)\left(\rho-r_{1}\right)-p r_{1}}{\left(1-s_{-n}\right) \rho-n r_{1} s_{-n+1}\left(\rho-r_{1}\right)} \quad[4] \text {. }
$$

I now proceed to give an example worked out at length, which will serve to exhibit the labour required in the process, and the degree of aecuracy attained. The case is one which actually occurred in practice.

Exampte.-A loan at four per cent., having twenty years to run, is purchased at the rate of $£ 1.09875$ per $£ 1$. Required the rate of interest obtained by the purchaser.

In Equation [3] we have $p=\cdot 09875$ and $a_{-n}=13 \cdot 59$.

$$
\begin{aligned}
& \lambda p=\overline{2} \cdot 99454 \\
& \lambda a_{-n}=1.13322 \\
& =04000=\rho \\
& \overline{3} \cdot 86132=\lambda \cdot 00727 \\
& .03273=1 \text { st approximation. }
\end{aligned}
$$

Assuming 0325 for the value of $r_{1}$, we obtain a second approximation by Equation [2] thus:-

$$
\begin{aligned}
& \cdot 04=\rho \quad 14.539\left(=a_{-n}\right) \times \cdot 0075 \quad 14.539 \times \cdot 04 \\
& \cdot 0325=r_{1} \\
& 3 \cdot 635 \\
& \overrightarrow{.0075}=\rho-r_{1} \quad \overrightarrow{\cdot 10904}=a_{-n} \times\left(\rho-r_{1}\right) \quad \cdot 07662=a_{-n} \cdot \rho \\
& \cdot 09875=p \\
& .01029=\text { numerator. }
\end{aligned}
$$

* Similarly, the amounts of a sum and annuity will be denoted sespectively by $s_{n}$ and $a_{n}$ 
$\cdot 5108\left(=s_{-n+1}\right) \times(\cdot 0075 \times 20=\cdot 15)$

$\cdot 2554$

$$
\begin{aligned}
& \cdot 07662=n s_{-\overline{n+1}}\left(\rho-r_{1}\right) \\
& \lambda r_{\mathrm{I}}=\overline{2} \cdot 51188 \\
& \lambda \text { Nnm. }=2 \cdot 01242 \\
& k \lambda \text { Den. }=\cdot 29676 \\
& \overline{\overline{4} \cdot 82106}=\lambda \cdot 0325000=r_{1} \\
& .0331623=2 \text { nd approximation. }
\end{aligned}
$$

The value of $r$ thus found is correct to the fifth decimal place-a repetition of the process by Equation [4], giving $r=\cdot 0331665$.

In the "Account of a Correspondence between Barrett and Baily," published in Vol. IV. of the Assurance Magazine, is the following extract from a letter written by the former:- "Your rule for approximating to the value of $\rho^{*}$ in your Annuities will be greatly improved by substituting for $\varepsilon^{*}$ (at the end of the denominator) the amount of $f 1$ per annum for $n$ years, at the assumed rate." Barrett here refers to Baily's method of finding the rate of interest in the "amounts" of annuities by successive approximations, and the improved formula which he recommends is obtained by a method similar to the foregoing. Thus, if $\mathrm{A}=$ the given amount of the annuity of $\mathfrak{E 1}$,

$$
\phi r=\phi\left(r_{1}+h\right)=\frac{(1+r)^{n}-1}{r}-\mathrm{A}=o ;
$$

as before, we have $h=-\frac{\phi r_{1}}{\phi^{\prime} r_{1}}$, which in the present case will be found to give $h=\frac{1+\mathrm{A} r_{1}-s_{n}}{n s_{n-1}-a_{n}}$. And proceeding in the same way with the "present values" of annuities, we have ( $\mathrm{V}$ being the given value)

$$
h=\frac{1-\mathrm{V}_{r_{1}}-s_{-n}}{a_{-n}-n s_{-\overline{n+1}}} .
$$

To render the use of these formulæ independent of interest tables, easy methods of obtaining a first approximation are wanted. I shall therefore conclude by sabmitting the following, which give the required result with considerable accuracy for the more practicable rates (viz., from three to five per cent.), and with very little trouble:-

$$
\begin{aligned}
& \text { In amounts of annuities, } r=\frac{4(\mathrm{~A}-n)}{(n-1)(\mathrm{A}+n)} . \\
& \text { In values of annuities, } r=\frac{8(n-\mathrm{V})}{(n+1)(3 \mathrm{~V}+n)} .
\end{aligned}
$$

The following table will give an idea of the extent to which they may be relied upon:-

* In Baily's notation, $\rho=$ the rate of interest songht, and $\frac{s}{a}=$ the given amount of the annuity of $£$. 


\begin{tabular}{|c|c|c|c|c|c|c|c|}
\hline \multicolumn{4}{|c|}{ Amounts of Annuities. } & \multicolumn{4}{|c|}{ Valnes of Annuities. } \\
\hline$n$. & $r=-03$ & $r=\cdot 04$ & $r=\cdot 05$. & n. & $r=\cdot 03$. & $r=-04$. & $r=\cdot 05$ \\
\hline 5 & $\cdot 0300$ & $\cdot 0400$ & .0499 & 5 & $\cdot 0299$ & $\cdot 0398$ & $\cdot 0497$ \\
\hline 20 & $\cdot 0309$ & $\cdot 0414$ & $\cdot 0518$ & 20 & $\cdot 0302$ & -0402 & $\cdot 0500$ \\
\hline 35 & $\cdot 0314$ & $\cdot 0419$ & .0519 & 35 & $\cdot 0302$ & •0399 & $=0492$ \\
\hline 50 & $\cdot 0315$ & .0414 & .0502 & 50 & $\cdot 0299$ & .0391 & -0475 \\
\hline
\end{tabular}

I am, Sir,

Your most obedient Servant,

London, 17 th August, 1855.

M.

\section{DECIMAL COINAGE.}

To the Editor of the Assurance Magazine.

$\mathrm{SIR}_{3}$-In Mr. Jellicoe's paper recently read before the Institute of Actuaries and printed in your Number for this month, it is stated (page 299) that I have addnced a certain multiplication, there referred to, as " an argunent against the Committee's plan." Such is not the fact.

In my short paper read before the Society of Arts in February last, to which reference is made, it will be seen that the figures quoted by $\mathbf{M r}$. Jellicoe form an example offered, not by me, but by Mr. Henry Taylor, in his published work on this subject, in which he has ased $11 \times 3+2$ to obtain the product of $£ 57.17 \mathrm{~s}$. $10 \mathrm{~d}$. by 35 , thereby increasing the number of figures in the working-a mode of procedure which $I$ protested against, as exhibiting an unfair contrast between the ordinary method and that by decimals. How, then, it conld be brought forward as an argument of mine "to show that such operations can be performed in the ordinary way by means of a less number of figures than by making the computation decimally," I am at a loss to discover. I hold no such opinion.

I am, Sir,

\section{Your obedient Servant,}

\section{Islington, July 24th, 1855.}

FREDERIC JAMES MINASI.

Note.-On referring to Mr. Minasi's paper, we observe that he adduces the calculation in question as an illustration of the following remark:"I am not willing to leave this part of the subject without noticing the attempts of certain exponents of the millesimal division of the sovereign to exhibit unfair contrasts between that system and the one in present use." He then shows that 58.856 (not 57.891) $\times 35$ takes 26 figures, and that 58. 17. $1 \frac{1}{2}$. $\times 5 \times 7$ takes 22 only, and says- "So much for prepared examples, than which there can be hardly anything more specious," \&c.

Mr. Jellicoe admits the truth of the illustration, but argues that the decimal process is notwithstanding the preferable one, on the score of the less time and labour (of thought) taken by it. The calculation quoted by Mr. Jellicoe is Mr. Minasi's, or Mr. Minasi's "sharp little fiend's," not Mr. Taylor's.-ED. $A$. $M$. 